\title{
COMPOSTOS FENÓLICOS E ATIVIDADE ANTI-TRÍPTICA EM TRÊS VARIEDADE DE UVAS
}

\author{
Fabiana Maria Coimbra de Carvalho
}

Universidade Federal do Rio Grande do Norte, Departamento de Nutrição, Campus Universitário, Lagoa Nova, Natal, RN, Brasil. E-mail: fabicoimbra@ hotmail.com

Marcela Berckmans Viégas Costa Dantas

Universidade Federal do Rio Grande do Norte, Departamento de Nutrição, Campus

Universitário, Lagoa Nova, Natal, RN, Brasil. E-mail: marcelaberckmans@ gmail.com

\section{Ágnes Denise de Lima Bezerra}

Universidade Federal do Rio Grande do Norte, Departamento de Nutrição, Campus

Universitário, Lagoa Nova, Natal, RN, Brasil. E-mail: agnes_denise@ hotmail.com

Richele Janaina de Araújo Machado

Universidade Federal do Rio Grande do Norte, Centro de Biociências, Departamento de

Bioquímica, Campus Universitário, Lagoa Nova, Natal, RN, Brasil. E-mail:

richeledbq@gmail.com

Elizeu Antunes dos Santos

Universidade Federal do Rio Grande do Norte, Centro de Biociências, Departamento de

Bioquímica, Campus Universitário, Lagoa Nova, Natal, RN, Brasil. E-mail: elizeu@ufrnet.br

Ana Heloneida de Araújo Morais

Universidade Federal do Rio Grande do Norte, Departamento de Nutrição, Campus

Universitário, Lagoa Nova, Natal, RN, Brasil. E-mail: aharaujomorais@ gmail.com

\section{RESUMO}

A ingestão de frutas associa-se a uma alimentação saudável, pois são importantes fontes de nutrientes e de compostos fenólicos nas dietas alimentares. Dentre as frutas, as uvas (Vittis $s p$ ) apresentam alto teor de compostos fenólicos, os quais apresentam diversos benefícios à saúde. Este estudo teve como objetivo detectar a atividade inibitória de tripsina em extratos de polpa e de sementes de três variedades (Isabel, Itália e Rubi) de uva (Vitis vinifera L.). Para tal foi realizada a detecção da presença da atividade antitríptica, como também a determinação do conteúdo de compostos fenólicos e a dosagem de proteínas solúveis. A partir desses testes foi detectada atividade inibitória de tripsina em todos os extratos analisados de uva verde (Itália), roxa (Isabel) e vermelha (Rubi) e, de acordo com o conteúdo proteico e de compostos fenólicos, a atividade antitríptica se deve à presença de polifenóis, uma vez que, em todos os extratos analisados, não foram quantificadas proteínas solúveis. Ressalta-se que as uvas são importantes fontes de compostos fenólicos e que os extratos das três variedades estudadas apresentaram atividade inibitória de tripsina, entretanto, não há relatos de trabalhos com evidências da associação do seu consumo com efeitos deletérios e, consequentemente, restrições para seres humanos. Sugere-se que estes inibidores, provavelmente, não proteicos e sim polifenóis, na quantidade e dose adequada devem estar muito mais relacionados a benefícios do que aos efeitos adversos, comumente atribuídos a estes tipos de compostos.

PALAVRAS-CHAVE: Vitis vinifera L., Inibidor de tripsina, Proteínas. 


\title{
PHENOLIC COMPOUNDS AND ANTITRYPTIC ACTIVITY FROM PULPLS AND SEEDS OF THREE VARIETIES OF GRAPES
}

\begin{abstract}
The fruit intake is associated with a healthy diet because they are important sources of nutrients and phenolic compounds in the diets. Among fruits, grapes (Vittis sp) have a high content of phenolic compounds, which have many health benefits. This study aimed to detect the trypsin inhibitory activity in extracts of pulp and seeds of three varieties (Itália, Isabel and rubi) of grape (Vitis vinifera L.). Tests were conducted in order to detect the presence of antitryptic activity, as well to determine the content of phenolic compounds and dosage of soluble proteins. Trypsin inhibitory activity was detected in those tests and in all assayed extracts, which were green grape (Itália), purple grape (Isabel) and red grape (rubi). Also, according to the protein content of phenolic compounds, the antitryptic activity occurs due to the presence of polyphenols, because, in all extracts tested, soluble proteins were not quantified. It is noteworthy that grapes are an important source of phenolic compounds and extracts of the three varieties studied showed trypsin inhibitory activity, however, also that there is evidence of the association works with its consumption, with deleterious effects and thus restrictions for humans. It is suggested that these inhibitors, probably non-protein, but the polyphenols, and the appropriate dosage amount must cause more benefits than hazards, related to adverse effects commonly allocated to these types of compounds.
\end{abstract}

KEYWORDS: Vitis vinifera L., Trypsin inhibitor, Proteins.

\section{COMPOSTOS FENÓLICOS E ATIVIDADE ANTI-TRÍPTICA EM TRÊS VARIEDADE DE UVAS}

\section{INTRODUÇÃO}

Alimentação saudável, geralmente, associa-se ao consumo de frutas, verduras, legumes, alimentos integrais e ao baixo consumo de lipídios, açúcares, sal, entre outros (BRASIL, 2006). Embasando estas associações, estudos recentes relacionam a ingestão de frutas e vegetais com propriedades antioxidantes e a diminuição do risco e desenvolvimento de algumas doenças crônico-degenerativas (LIMA; MELO; LIMA, 2002; DEGÁSPARI; WASZCZYNSKYJ, 2004; GARCÍA-ALONSO et al., 2004; SILVA et al., 2004; WICKLUND et al., 2005; KUSKOSKI et al., 2006; JARDINI et al., 2010). Dentre as frutas, a uva (Vitis vinifera L.) é uma das mais cultivada no mundo, e representa um componente essencial para a dieta e cultura mediterrânea. Nos últimos anos, tem se tornado importante, também, na geração de emprego em grandes empreendimentos, que produzem uvas de mesa e uvas para processamento, sendo a vitivinicultura uma atividade importante para a sustentabilidade da pequena propriedade no Brasil (MELLO, 2012).

Além da importância econômica, os subprodutos do suco de uva, da produção de vinho e as mais diversas variedades de uvas, por apresentarem a coloração verde, vermelha, roxa ou azul, são consideradas uma das maiores fontes de compostos fenólicos quando comparadas a outras frutas e vegetais, visto que são ricas em fitoquímicos, como os flavonóides (catequina, epicatequina, procianidinas e antocianinas), ácidos fenólicos e resveratrol, os quais são pigmentos antioxidantes que, quando combinados, são responsáveis pela coloração da fruta (SHRIKHANDE, 2000; TORRES; BOBET, 2001; 
ORAK, 2007; SOARES et al., 2008; VEDANA et al., 2008; KOYAMA et al., 2012; NOVAK et al., 2008; CORRALES et al., 2010).

Neste contexto, o consumo de frutas in natura vem aumentando na dieta das pessoas que buscam maior valor nutritivo, efeitos terapêuticos e diferentes fitoquímicos (MAXCHEIX; FLEURIET; BILLOT, 1990; ANJO, 2004; MELO et al., 2008).

No entanto, a uva, ao ser consumida in natura, comumente, é ingerida junto às suas sementes e, mesmo diante dos inúmeros benefícios à saúde apresentados, especialmente relacionados ao consumo da polpa, é imprescindível também investigar a presença de inibidores enzimáticos nas suas sementes, tendo em vista a possibilidade de interferirem na alegação de saúde ou no aspecto nutritivo desta fruta, por conter moléculas e/ou compostos com características antinutricionais, isto é, que podem interferir na biodisponibilidade e/ou digestibilidade de nutrientes.

$\mathrm{Na}$ literatura, encontram-se diversas evidências de que as sementes de leguminosas e frutas e mesmo as suas polpas contêm fatores antinutricionais inerentes ao próprio alimento (XAVIER-FILHO, 1993; GUSTAFSSON; SANDBERG, 1995; UMMADI; CHENOWETH; VEBEERSAX, 1995; ARAÚJO et al., 2004), entre eles os inibidores de proteases (tripsina e quimiotripsina), ácido fítico, taninos que podem levar a uma diminuição da qualidade nutricional, pelo fato de promover a baixa biodisponibilidade de proteínas e aminoácidos, carboidratos, vitaminas e minerais, pela formação de complexos, (VARGAS; BRASSANI; NAVARRETE, 1984; LUI, 1995; NAVES et al., 2010) por isso a importância de se estudar estes inibidores em frutas que são consumidas geralmente íntegras, inclusive com as suas sementes.

Entretanto, diversos trabalhos vêm sendo divulgados demonstrando também os efeitos benéficos dos inibidores enzimáticos, os quais têm sido apresentados demonstrando capacidade anticarcinogênica, anticoagulante, antidiabetes e redução de doenças cardiovasculares, bem como na atuação anti-inflamatória, antiproliferativa, além de outras (KENNEDY, 1998; ZHANG et al., 1999; OLIVA et al., 2000; UUSIKU et al., 2010).

Ainda, diversos estudos mostram que o ácido fítico e os compostos fenólicos contribuem beneficamente ao organismo humano, especialmente os flavonóides (antoxantinas e antocianinas) devido às suas funções antioxidantes (HEIM; TAGLIAFERRO; BOBILYA, 2002; KUSKOSKI et al., 2006). Ainda dentre essas funções, merecem destaque a ação anticarcinogênica e contribuição nutricional como sacietogênico, (WANG; MAZZA, 2002; ROSS; KASUM, 2002; KATSUBE et al., 2003) na prevenção de doenças cardiovasculares e circulatórias, neurológicas (NESS; POWLES, 1997; ISHIGE; SCHUBERT; SAGARA, 2001; STOCLET et al., 2004), além de possuírem atividades anti-inflamatórias, antialérgicas, antitrombótica e antimicrobiana (SÁNCHEZ-MORENO, 2002).

Considerando que a uva é uma fruta bastante consumida e que existe a possibilidade de haver inibidores enzimáticos em suas sementes ou até mesmo na sua polpa, é importante investigar não só as suas propriedades nutricionais, mas também detectar a presença de inibidor de tripsina que são singulares e que, mediante à utilização de técnicas apropriadas, podem inclusive ser de interesse na área biotecnológica.

\section{MATERIAIS E MÉTODOS}




\section{Material biológico}

As uvas das variedades Isabel (roxa), Itália (verde) e Rubi (vermelha) foram obtidas comercialmente na cidade de Natal-RN. Os experimentos foram desenvolvidos no Laboratório de Química de Proteínas Bioativas Prof. Mauricio Pereira de Sales do Departamento de Bioquímica da UFRN.

\section{Preparo do extrato bruto de polpa e semente das frutas}

As frutas foram descascadas e tiveram sua polpa e sementes extraídas manualmente. Cada fruta constituiu polpa de fruta e semente. Para o preparo dos extratos bruto das variedades de cada fruta, as sementes foram secas em estufa ventilada a $45{ }^{\circ} \mathrm{C}$ e, em seguida, trituradas em moinho industrial resfriado $\left(6{ }^{\circ} \mathrm{C}\right)$, a polpa de fruta foi trituradas em liquidificador doméstico. Em seguida, elas foram pesadas e submetidas à extração, que ocorreu em tampão Tris-HCL 0,05 mM, pH 7,5, na proporção $1: 10$ (p/v) sob 3 horas de agitação constante. Após a agitação, foram centrifugadas a $4{ }^{\circ} \mathrm{C}$ durante 30 minutos na frequiência de $8000 \times \mathrm{g}$. Em seguida, a solução heterogênea obtida foi filtrada com auxílio de funil e algodão e o sobrenadante denominado extrato bruto solúvel.

\section{Atividade inibitória para tripsina}

As atividades inibitórias de tripsina nos extratos das três variedades de uva foram medidas em triplicata e determinadas como descrito por Kakade, Simons e Liener (1969) com uso do substrato BAPNA $0,0125 \mathrm{mM}$. O resultado foi mensurado por meio de leitura em espectrofotômetro a $410 \mathrm{~nm}$ e expressos em UI (unidade de inibição) / $100 \mu \mathrm{L}$ de extrato, em que a unidade de inibição representa a diferença entre a atividade enzimática da enzima (controle) e dos testes (extratos), sendo 1 UI igual a $0,01 \mathrm{~nm}$.

\section{Avaliação dos compostos fenólicos totais}

O conteúdo de fenólicos totais foi medido em triplicata, usando o reagente FolinCiocalteau e como padrão o ácido gálico $(10 \mathrm{mg} / \mathrm{mL})$, conforme o método de Swain e Hills (1959). O ácido gálico foi diluído para $1 \mathrm{mg} / \mathrm{mL}$ e $0,1 \mathrm{mg} / \mathrm{ml}$ em bicarbonato de sódio a 20\%. A curva analítica, desse modo, foi construída contendo 200, 100, 50, 20, 10, 1 $\mu \mathrm{g} . \mathrm{mL}^{-1}$ de ácido gálico. As leituras das absorbâncias foram realizadas a $765 \mathrm{~nm} \mathrm{em}$ espectrofotômetro. Os resultados foram expressos em $\mathrm{mg}$ de equivalentes de ácido gálico / $100 \mu \mathrm{L}$ de extrato.

\section{Dosagem de proteínas totais solúveis}

Todas as determinações proteicas foram realizadas em triplicata pelo método de Bradford (1976). As leituras das absorbâncias foram realizadas a $595 \mathrm{~nm}$ em espectrofotômetro. Os resultados foram expressos em $\mu \mathrm{g}$ de proteínas solúveis/ $\mu \mathrm{L}$ de extrato.

\section{Análise estatística}

Os dados foram tabulados e analisados por meio de estatística descritiva usando medidas de tendência central e de dispersão (desvio padrão) utilizando o programa Microsoft Excel®, versão XP. 


\section{RESULTADOS}

\section{Atividade inibitória para tripsina}

Os resultados das atividades inibitórias de tripsina dos extratos de polpa de uva verde, uva roxa e uva vermelha, revelaram que tanto as uvas verdes quanto as roxas apresentaram maior atividade inibitória de tripsina comparada às uvas vermelhas. Os extratos de semente também apresentaram atividade antitríptica, como pode ser observado nos Gráficos 1 e 2 , respectivamente.

Gráfico 1: Atividade inibitória de tripsina do extrato bruto solúvel de polpa de uvas das variedades Isabel (roxa), Itália (verde) e Rubi (vermelha). Os dados são expressos em UI (unidade de inibição) / $100 \mu \mathrm{L}$ de extrato e apresentados como média \pm desvio padrão.

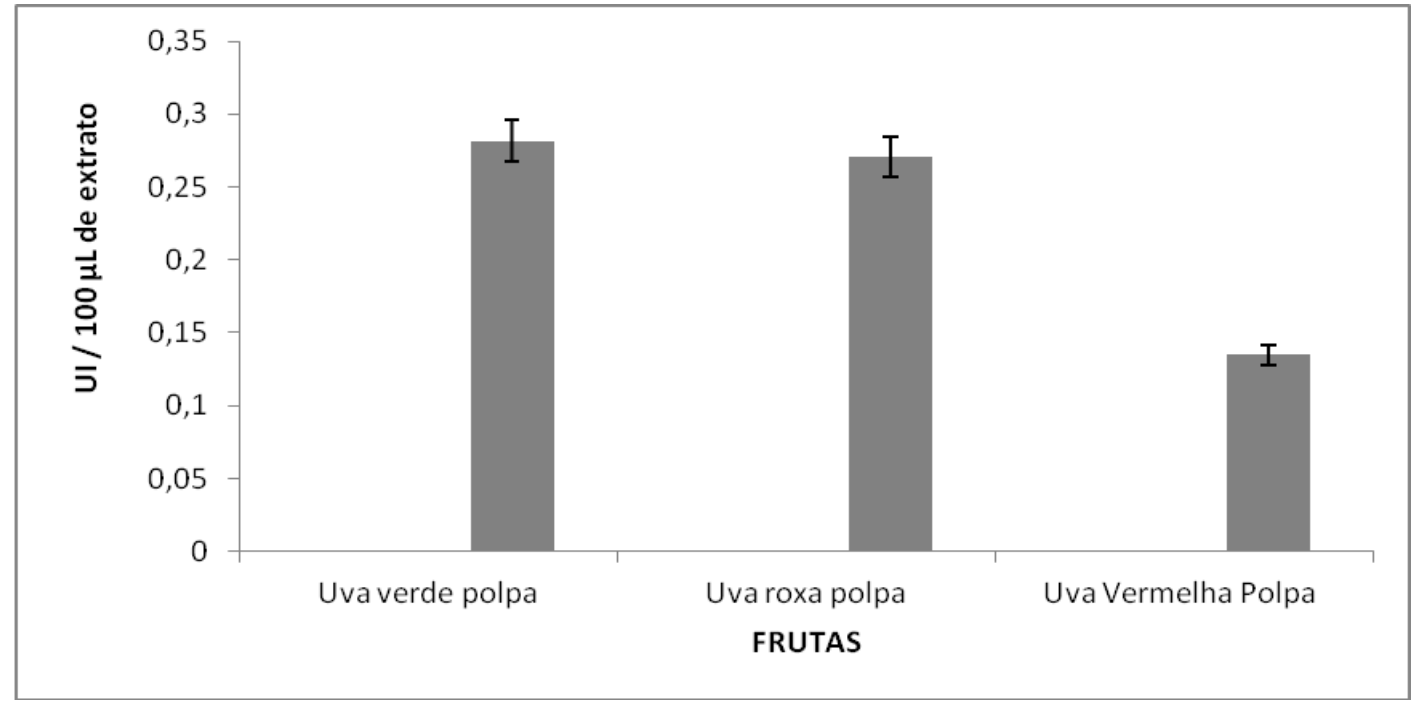

Gráfico 2: Atividade inibitória de tripsina do extrato bruto solúvel de sementes de uvas das variedades Isabel (roxa), Itália (verde) e Rubi (vermelha). Os dados são expressos em UI (unidade de inibição) / $100 \mu \mathrm{L}$ de extrato e apresentados como média \pm desvio padrão.

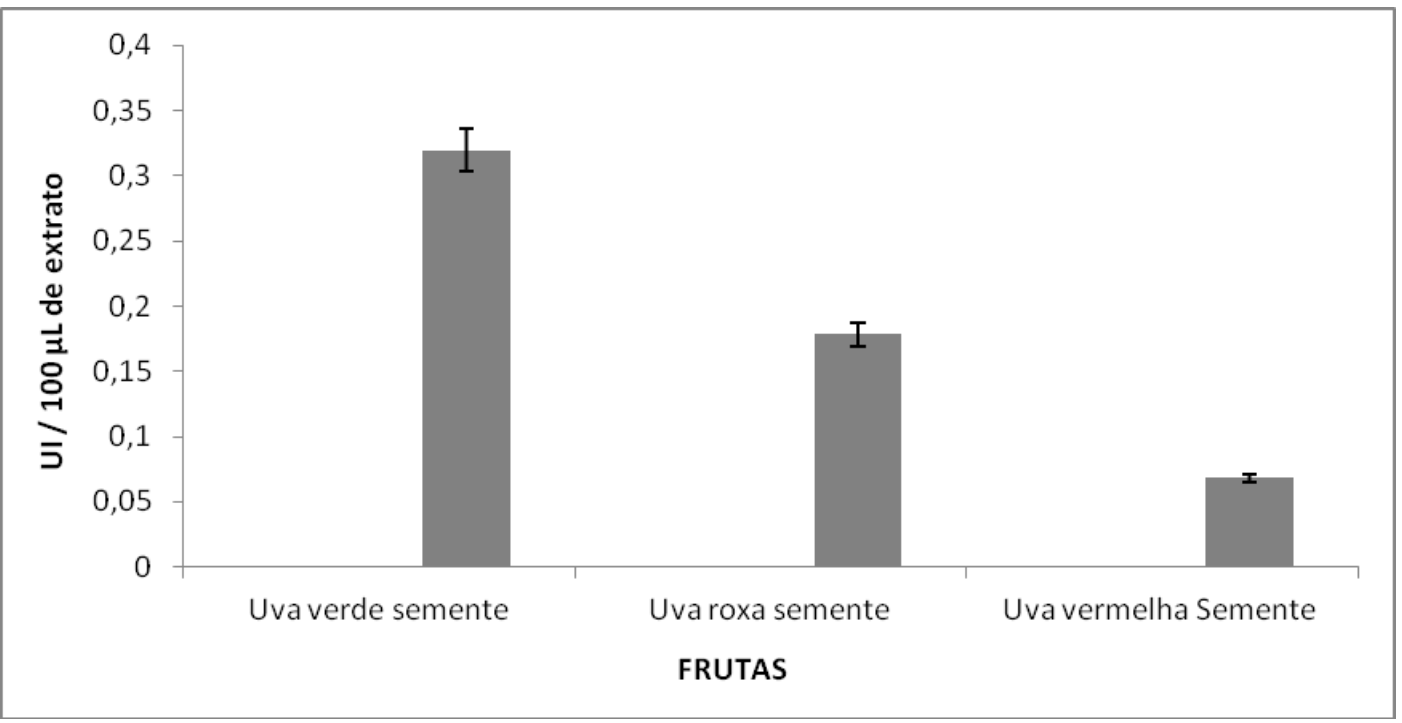




\section{Avaliação dos compostos fenólicos totais}

Os resultados de compostos fenólicos dos seis extratos de polpa e semente de uva vermelha, verde e roxa mostraram que o extrato de polpa da uva vermelha possui a maior quantidade de compostos fenólicos, conforme apresenta os Gráficos 3 e 4, respectivamente.

Gráfico 3: Conteúdo de compostos fenólicos do extrato bruto solúvel de polpa de uvas das variedades Isabel (roxa), Itália (verde) e Rubi (vermelha). Os resultados são expressos como equivalentes de miligramas de ácido gálico/100 $\mu \mathrm{l}$ e apresentados como média \pm desvio padrão.

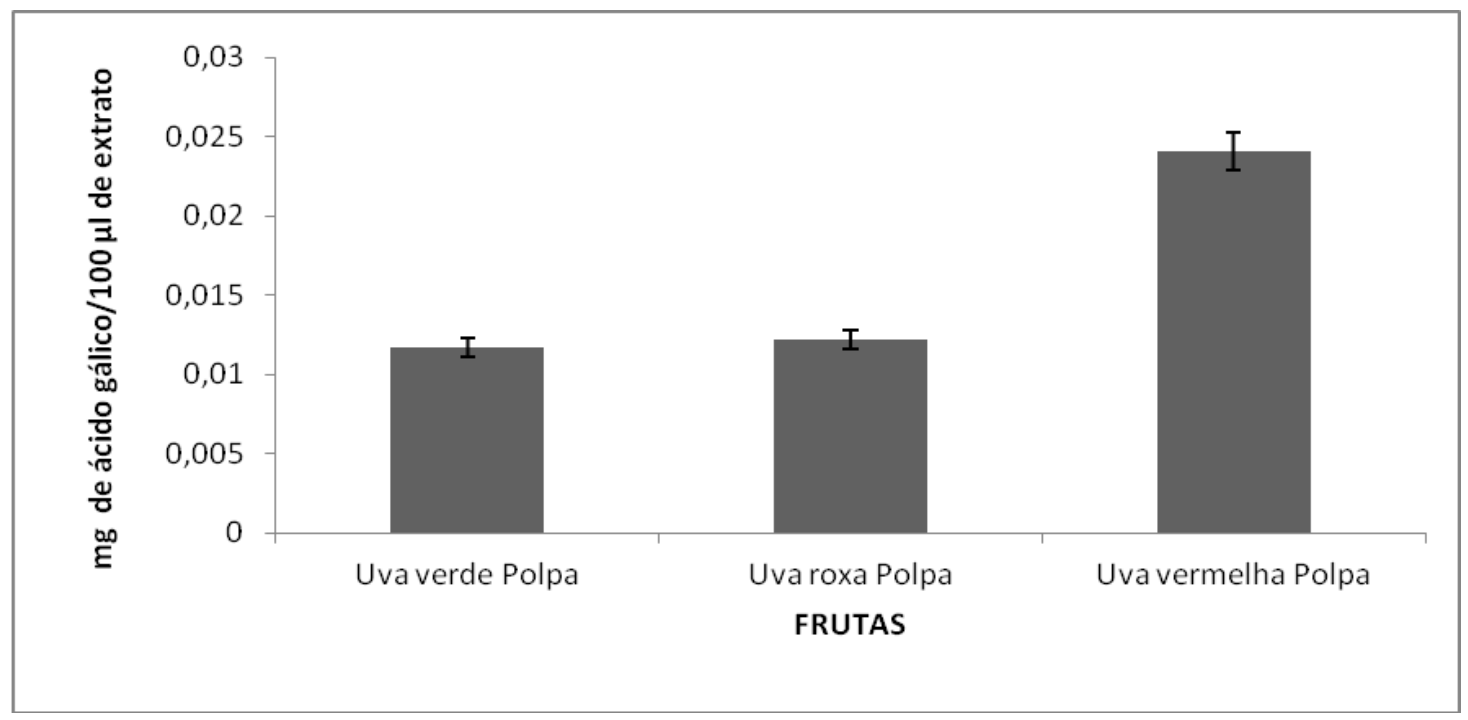

Gráfico 4: Conteúdo de compostos fenólicos do extrato bruto solúvel de sementes de uvas das variedades Isabel (roxa), Itália (verde) e Rubi (vermelha). Os resultados são expressos como equivalentes de miligramas de ácido gálico/100 $\mu \mathrm{l}$ de extrato e apresentados como média \pm desvio padrão.

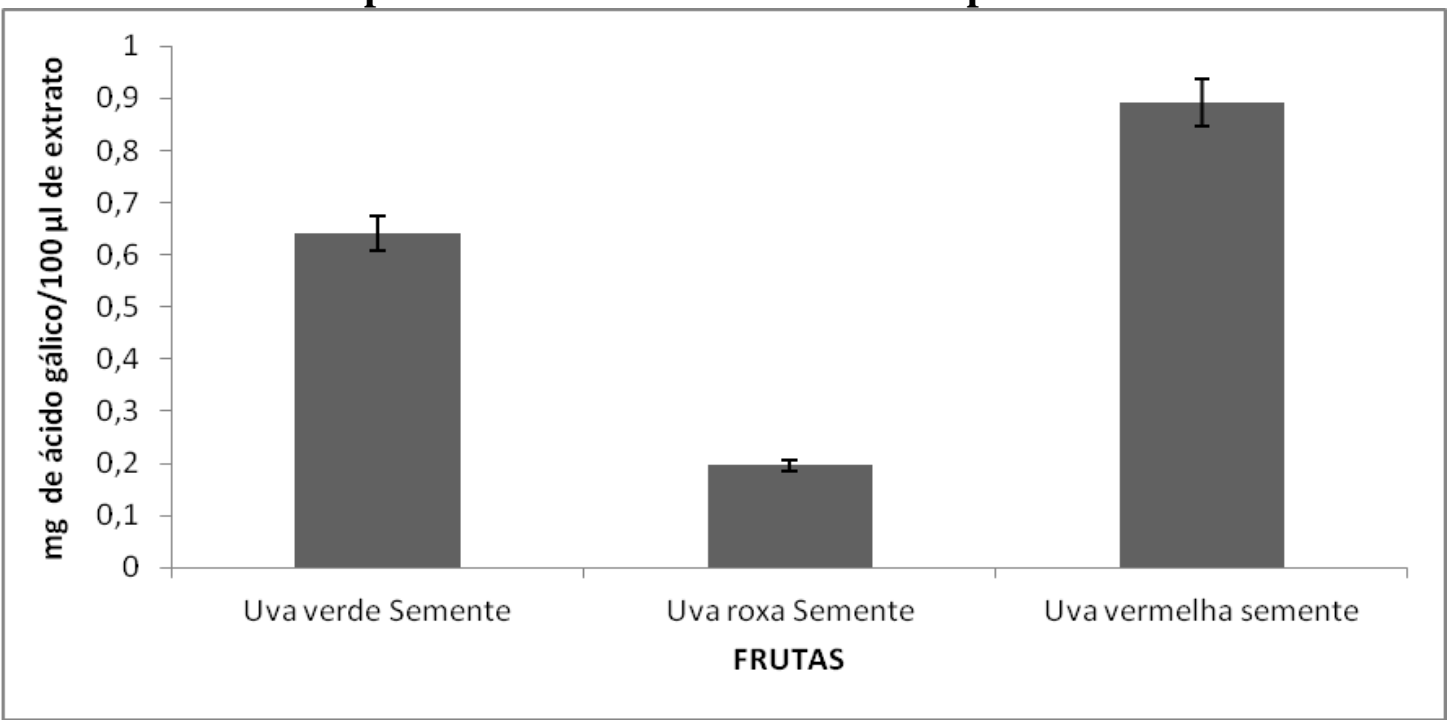




\section{Dosagem de proteínas totais solúveis}

Os resultados referentes à dosagem de proteínas, ou seja, à quantidade de proteínas solúveis para todos os extratos de polpa e semente de uva demonstra que a quantidade de proteínas solúveis é insignificante para os seis extratos analisados.

\section{DISCUSSÃO}

Os inibidores de proteases tanto podem ser do tipo proteico quanto do tipo fenólico e interferem na atividade de sistemas enzimáticos inibindo proteases (SINGH; KRIKORIAN, 1982; AW; SWANSON, 1985; BODE; HUBER, 1992). Os inibidores de proteases que diminuem ou cessam a atividade de enzimas proteolíticas, em polpa de frutas, frutos, sementes e plantas têm sido detectados, isolados e purificados (XAVIERFILHO, 1993; ARAÚJO et al., 2004; HAQ; ATIF; KHAN, 2005; SANTOS et al., 2012). Além dos inibidores proteicos, os compostos, destacando entre vários, os taninos e os fitatos também atuam como inibidores enzimáticos (AW; SWANSON, 1985; GUSTAFSSON; SANDBERG, 1995). Vale ressaltar que as frutas e, dentre elas as uvas, são ricas fontes de compostos fenólicos (ORAK, 2007; CORRALES et al., 2010).

Quanto à atividade inibitória de tripsina, pode-se constatar que, em todos os extratos de uva verde, roxa e vermelha, foram detectadas inibição de tripsina. Ainda, no estudo em questão, foi constatada a presença de compostos fenólicos nos extratos analisados, no entanto, ao ser realizada a quantificação proteica, foi visto que, nos extratos, não foi verificada a presença de proteínas solúveis, sendo, portanto, descartada a possibilidade da atividade inibitória detectada, nos extratos de frutas estudados, devido a algum inibidor do tipo proteico.

Corroborando com esta afirmação em outros estudos, com extratos de polifenóis de peras, cacau e lentilhas, foi verificada a inibição da enzima tripsina. No entanto a composição fenólica não foi elucidada, supondo-se que teriam, nestes extratos, proantocianidinas ou taninos condensados (QUESADA et al., 1996). Outros estudos somam-se a este também revelando a ação inibitória de compostos, tais como os fitatos e os taninos (AW; SWANSON, 1985; GUSTAFSSON; SANDBERG, 1995; SILVA; SILVA, 1999).

Em uvas, o estudo realizado por Gonçalves (2007) revela que, em grainha da uva e em vinhos de mesa, houve atividade inibitória de tripsina causada pelos compostos bioativos, e, no que diz respeito aos sumos da fruta, verificou-se uma relação direta entre o conteúdo de fenóis totais e a inibição enzimática.

Nos extratos das uvas estudados, observa-se que, apesar de os extratos das sementes possuírem uma quantidade elevada de compostos fenólicos, comparada aos extratos de polpa, tanto os extratos de polpa como os de sementes apresentaram atividades inibitórias semelhantes. Os fenóis poliméricos, que estão mais relacionados com a inibição de enzimas, como a tripsina, são especialmente o tanino e o ácido fítico e estando presentes tanto nas polpas quanto nas sementes (SALUNKHE et al., 1982; GOMEZ-CORDOVÉS; GONZÁLEZ-SANJOSE, 1995; SILVA; SILVA, 1999). Sendo assim, ao levar em consideração que essas frutas são ricas em compostos fenólicos, mas que apresentam tipos e concentrações diferentes dependendo da localização nas diferentes partes da fruta, na polpa, mesmo predominado compostos fenólicos que não se relacionam com a atividade inibitória enzimática, pode haver além dos taninos ou fitatos que se relacionam muito bem 
com a propriedade inibitória (NAVES et al., 2010), os compostos fenólicos de plantas, tais como antocianinas, bioflavonóides e catequinas, presentes especialmente nas uvas roxas e vermelhas, que também podem inibir a atividade de enzimas digestivas como a alfaamilase, tripsina, quimotripsina e lipase (SALUNKHE et al., 1982). Dessa forma, torna-se necessário identificar os compostos presentes nos extratos de uva verde, roxa e vermelha para poder afirmar qual é o responsável pela inibição.

Nos alimentos, sob condições naturais, o ácido fítico encontra-se carregado negativamente, o que the confere alto potencial para se complexar com moléculas carregadas positivamente como cátions e proteínas (CHERYAN, 1980; SILVA; SILVA, 1999). Ainda, segundo Cheryan (1980), no caso das proteínas, o ácido fítico pode formar complexos em $\mathrm{pH}$ ácido ou alcalino, desde que, as proteínas estejam abaixo ou acima do $\mathrm{pH}$ isoelétrico.

Neste estudo, os extratos e as atividades inibitórias foram obtidos e detectadas em $\mathrm{pH}$ 7,5, o que pode ter favorecido a formação dos complexos. Muitos desses complexos são insolúveis e biologicamente indisponíveis para seres humanos em condições fisiológicas normais (SILVA; SILVA, 1999).

Visto que as uvas são importantes fontes de compostos fenólicos e que os extratos das três variedades estudadas apresentaram atividade inibitória de tripsina, é importante ressaltar que o consumo desta fruta é totalmente recomendado, graças exatamente à presença dos compostos fenólicos e as atividades benéficas a eles atribuídas. Ademais, por não existirem trabalhos com evidências da associação do seu consumo aos efeitos deletérios em seres humanos, este estudo revela dados que podem contribuir, possivelmente, ainda mais com a alegação de saúde desta fruta, uma vez que existem, atualmente, diversos estudos sobre medicamentos que inibem enzimas proteolíticas, e tem sido desenvolvida uma série de inibidores enzimáticos aplicados em estudos in vitro e em animais relacionados a efeitos benéficos à saúde. No entanto, se faz necessário, para a determinação de um consumo saudável, investigar os possíveis efeitos maléficos correlacionando-os com doses e frequência de consumo.

\section{CONCLUSÕES}

Diante desse contexto, sabe-se que as uvas são importantes fontes de compostos fenólicos e estes podem atuar como inibidor de tripsina. Como não foi possível quantificar proteínas solúveis nos extratos estudados, e diante do conteúdo de compostos fenólicos presente nestes mesmos extratos, evidencia-se que os inibidores de tripsina detectados nas uvas provavelmente não são proteínas e sim polifenóis. Detectar a existência desses compostos com atividades biológicas em frutas, nesse caso inibindo enzimas, além de serem apontados como possíveis novos bioprodutos a serem usados como bioinseticidas, biofungicidas, bactericidas e também como biofármacos, destaca-se como um dos mais promissores campos de bioprospecção destas biomoléculas, levando em considerações as alegações de saúde atribuídas às frutas de uma forma geral.

\section{REFERÊNCIAS BIBLIOGRÁFICAS}

1. ANJO, D. L. C. Alimentos funcionais em angiologia e cirurgia vascular. J Vasc Bras, v. 3, n. 2, p. 145-154, 2004. 
2. ARAÚJO, C. L.; BEZERRA, I. W. L.; DANTAS, I. C.; LIMA, T. V. S.; OLIVEIRA, A. S.; MIRANDA, M. R. A.; LEITE, E. L.; SALES, M. P. Biological activity of proteins from pulpls of tropical fruits. Food Chem, v. 5, p. 107-110, 2004.

3. AW, T. L.; SWANSON, B. G. Influence of tannin on Phaseolus vulgaris protein digestibility and quality. J Food Sci, v. 50, n. 1, p. 67-71, 1985.

4. BODE, W.; HUBER, R. Natural protein proteinase inhibitors and their interaction whith proteinases. Eur J Biochem, v. 204, n. 2, p. 433-451, 1992.

5. BRADFORD, M. M. A rapid and sensitive method for the quantitation of microgram quantities of protein utilizing the principle of dye binding. Anal Biochem, v. 72, p. 248254, 1976.

6. BRASIL. Ministério da Saúde. Guia alimentar para a população brasileira: promovendo a Alimentação saudável. Brasília: Ministério da Saúde, 2006. p. 284.

7. CHERYAN, M. Phytic acid interactions in food systems. CRC Crit Rev Food Sci Nutr, v. 13, n. 4, p. 297-335, 1980.

8. CORRALES, M.; FERNANDEZ, A.; PINTO, M. G. V.; BUTZ, P.; FRANZ, C. M. A. P.; SCHUELE, E.; TAUSCHER, B. Characterization of phenolic content, in vitro biological activity, and pesticide loads of extracts from white grape skins from organic and conventional cultivars. Food Chem Toxicol, v. 48, p. 3471-3476, 2010.

9. DEGÁSPARI, C. H.; WASZCZYNSKYJ, N. Antioxidants Properties of Phenolic Compounds. Vis Academic, v. 5, n. 1, p. 33-40, 2004.

10. DELMAS, D.; JANNIN, B.; LATRUFFE, N. Resveratrol: Preventing properties against vascular alterations and ageing. Mol Nutr Food Res, v. 49, p. 377-395, 2005.

11. GARCÍA-ALONSO, M.; PASCUAL-TERESA, T.; SANTOS-BUELGA, C.; RIVAS-GONZALO, J. C. Evaluation of the antioxidant properties of fruits. Food Chem, v. 84, p. 13-18, 2004.

12. GOMEZ-CORDOVÉS, M. C.; GONZÁLEZ-SANJOSE, M. L. Interpretação de variáveis de cor durante o envelhecimento de vinhos tintos: relação com as famílias de compostos fenólicos. Rev Agric Alim Quím, v. 43, p. 557-561, 1995.

13. GONÇALVES, R. M. F. Estudo da inibição de tripsina por compostos fenólicos isolados de fontes naturais: efeito antinutricional de bebidas comuns. Portugal, 2007. Tese de Mestrado em Tecnologia Ciência e Segurança Alimentar-Faculdade de Ciências da Universidade do Porto, 2007.

14. GUSTAFSSON, E. L.; SANDBERG, A. S. Phytate reduction in brown beans (Phaseolus vulgaris L.). J Food Sci, v. 60, p. 149-152, 1995.

15. HAQ, S. K.; ATIF, S. M.; KHAN, R. H. Biochemical characterization, stability studies and $\mathrm{N}$-terminal sequence of a bi-functional inhibitor from Phaseolus aureus Roxb. (Mung bean). Int J Biochem Mol Biol, v. 87, n. 12, p. 1127-1136, 2005.

16. HEIM, K. E.; TAGLIAFERRO, A. R.; BOBILYA, D. J. Flavonoid antioxidants: chemistry, metabolism and structure-activity relationships. J Nutr Biochem, v. 13, n. 10, p. 572-584, 2002.

17. ISHIGE, K.; SCHUBERT, D.; SAGARA, Y. Flavonoids protect neuronal cells from oxidative stress by three distinct mechanisms. Free Radic Biol Med, v. 30, n. 4, p. 433446, 2001. 
18. JARDINI, F. A.; LIMA, A.; MENDONÇA, R. M. Z.; PINTO, R. J.; MANCINI, D. A. P.; MANCINI-FILHO, J. Compostos fenólicos da polpa e sementes de Romã (punica granatum, 1.): atividade antioxidante e Protetora em células mdck. Alim Nutr, Araraquara, v. 21, n. 4, p. 509-517, out./dez. 2010.

19. KAKADE, M. L.; SIMONS, N.; LIENER, I. E. Anevaluation of natural vs. synthetic substrates for measuring the antitryptic activity of soybean samples. J Cereal Chem, v. 46, p. 518, 1969.

20. KATSUBE, N.; KEIKO, I.; TSUSHIDA, T.; YAMAKI, K.; KOBORI, M. Induction of apoptosis in cancer cells by bilberry (Vaccinium mirtillus) and the anthocyanins. $\mathrm{J}$ Agric Food Chem, v. 51, p. 68-75, 2003.

21. KENNEDY, A. R. The Bowman-Birk inhibitor from soybeans as an anticarcinogenic agent. Am J Clin Nutr, v. 68, n. 6, p. 1406S-1412S, 1998.

22. KOYAMA, K.; IKEDA, H.; POUDEL, P. R.; GOTO-YAMAMOTO, N. Light quality affects flavonoid biosynthesis in young berries of Cabernet Sauvignon grape. Phytochem, v. 78, p. 54-64, 2012.

23. KUSKOSKI, E. M.; ASUERO, A.; MORALES, M.; FETT, R. Frutos tropicais silvestres e polpas de frutas congeladas: atividade antioxidante, polifenóis e antocianinas. Cienc Rural, Santa Maria, v. 36, n. 4, p. 1283-1287, jul/ago. 2006.

24. LIMA, V. L. A. G.; MELO, E. A.; LIMA, D. E. S. Fenólicos e carotenóides totais em pitanga. Sci Agric, v. 59, n. 3, 2002.

25. LUI, K. Celular biological and physicochemical basic for the hard-to-cook defect in legumes seeds. CRC Crit Rev Food Sci Nutr, v. 35, p. 263, 1995.

26. MAXCHEIX, J. J.; FLEURIET, A.; BILLOT, J. The main phenolics of fruits. In: Fruit Phenolics. CRC Press: Boca Raton, 1990, p.1-98.

27. MELLO, L. M. R. Vitivinicultura brasileira: panorama 2011. EMBRAPA Uva e Vinho, 2011. Disponível em: http://www.cnpuv.embrapa.br/publica/artigos/prodvit2010.pdf. Acesso em 20 mar. 2012.

28. MELO, E. A.; MACIEL, M. I. A.; LIMA, V. L. A. G.; NASCIMENTO, R. J. Capacidade antioxidante de frutas. Rev Bras Cienc Farm, v. 44, n. 2, p. 193-201, 2008.

29. NAVES, L. P.; CORREAA, A. D.; SANTOS, C. D.; ABREU, C. M. P. Componentes antinutricionais e digestibilidade proteica em sementes de abórbora (Cucurbita máxima) submetidas a diferentes processamentos. Cienc Tecnol Alim, Campinas, v. 30, n. 1, p. 180-184, maio. 2010.

30. NESS, A. R.; POWLES, J. W. Fruit and vegetables, and cardiovascular disease: a review. Int J Epidemiol, v. 26, n. 1, p. 1-13, 1997.

31. NOVAK, I.; JANEIRO, P.; SERUGA, M.; OLIVEIRA-BRETT, A. M. Ultrasound extracted flavonoids from four varieties of Portuguese red grape skins determined by reverse-phase high-performance liquid chromatography with electrochemical detection. Anal Chim Acta, v. 630, p. 107-115, 2008.

32. OLIVA, M. L.; SOUZA-PINTO, J. C.; BATISTA, I. F.; ARAUJO, M. S.; SILVEIRA, V. F.; AUERSWALD, E. A.; MENTELE, R.; ECKERSKORN, C.; SAMPAIO, M. U.; SAMPAIO, C. A. Leucaena leucocephala serine proteinase 
inhibitor: primary structure and action on blood coagulation, kinin release and rat paw edema. Biochim Biophys Acta, v. 1477, n. 1-2, p. 64-74, 2000.

33. ORAK, H. H. Total antioxidant activities, phenolics, anthocyanins, polyphenol oxidase activities of selected red grape cultivars and their correlations. Sci Hort, v. 111, p. 235-241, 2007.

34. QUESADA, C.; BARTOLOMÉ, B.; NIETO, O.; GÓMEZ-CORDOVÉS, C.; HERNÁNDEZ, T.; ESTRELLA, I. Phenolic Inhibitors of alpha-Amylase and Trypsin Enzymes by Extracts From Pears, Lentils, and Cocoa. J Food Protect, v. 59, p. 185-192, 1996.

35. ROSS, J. A.; KASUM, C. M. Dietary Flavonoids: Bioavailability, metalic effects, and safety. Annu Rev Nutr, v. 22, p. 19-34, 2002.

36. SALUNKHE, D. K.; JADHAV, S. J.; KADDAM, S. S.; CHAVAN, J. K. Chemical, biochemical and biological significance of polyphenol in cereals and legumes. CRC Crit Rev Food Sci Nutr, v. 17, p. 277-279, 1982.

37. SÁNCHEZ-MORENO, C. Compuestos polifenólicos: efectos fisiológicos. Actividad antioxidante. Alim, n. 329, p. 29-40, 2002.

38. SANTOS, E. A.; OLIVEIRA, A. S.; RABÊLO, L. M. A.; UCHÔA, A. F.; MORAIS, A. H. A. Affinity Chromatography as a Key Tool to Purify Protein Protease Inhibitors from Plants (2012). Affinity Chromatography. Disponpivel em: http://www.intechopen.com/books/howtoreference/affinity-chromatography/affinitychromatography-as-a-key-tool-to-purify-protease-inhibitors-from-plants. Acesso em: 01 de maio de 2012.

39. SHRIKHANDE, A. J. Wine by-products with health benefits. Food Res Int, v. 33, p. 469-474, 2000.

40. SILVA, B. M.; ANDRADE, P. B.; VALENTÃO, P.; FERRERES, F.; SEABRA, R. M.; FERREIRA, M. A. Quince (Cydonia oblonga Miller) Fruit (Pulp, Peel and Seed) and Jam: antioxidant activity. J Agric Food Chem, v. 52, n. 15, p. 4705-4712, 2004.

41. SILVA, M. R.; SILVA, A. A. P. Aspectos nutricionais de fitatos e taninos. Rev Nutr, v. 12, p. $5-19,1999$.

42. SINGH, M.; KRIKORIAN, A. D. Inhibiton of trypsin activity in vitro by phytate. J Agric Food Chem, v. 30, n. 4, p. 799-800, 1982.

43. SOARES, M.; WELTER, L.; KUSKOSKI, E. M.; GONZAGA, L.; FETT, R. Compostos fenólicos e atividade antioxidante da casca de Uvas Niágara e Isabel. Rev Bras Frutic, v. 30, n. 1, p. 59-64, 2008.

44. STOCLET, J. C.; CHATAIGNEAU, T.; NDIAYE, M.; OAK, M. H.; EL BEDOUI, J.; CHATAIGNEAU, M.; SCHINI-KERTH, V. B. Vascular protection by dietary polyphenols. Eur J Pharmacol, v. 500, n. 1-3, p. 299-313, 2004.

45. SWAIN, T.; HILLS, W. E. The phenolic constituents of Punnus domestica. Iquantitative analysis of phenolic constituents. J Sci Food Agric, v. 19, p. 63-68, 1959.

46. TORRE, M.; RODRIGUEZ, A. R.; SAURA-CALIXTO, F. Effects of dietary fiber and phytic acid on mineralavailability. Crit Rev Food Sci Nutr, v. 1, p. 1-22, 1991.

47. TORRES, J. L.; BOBET, R. New flavanol derivatives from grape (Vitis vinifera) by products: antioxidant aminoethylthio-flavan-3-ol conjugates from a polymeric waste 
fraction used as a source of flavanols. J Agric Food Chem, Washington, v. 49, p. 46274634, 2001.

48. UMMADI, P.; CHENOWETH, W. L.; VEBEERSAX, M. A. The influence of extrusion processing on iron dialyability, phytates and tannins in legumes. J Food Process Preserv, v. 19, p. 119-131, 1995.

49. UUSIKU, N. P.; OELOFSE, A.; DUODU, K. G.; BESTER, M. J.; FABER, M. Nutritional value of leafy vegetables of sub-Saharan Africa and their potential contribution to human health: A review. J Food Compos Anal, v. 23, n. 6, p. 499-509, 2010.

50. VARGAS, E.; BRASSANI, R.; NAVARRETE, D. Digestibilidad de la proteína y energia de dietas elaboradas a base de arroz y frijoles en humanos adultos. Arch Latinoam Nutr, v. 34, n. 1, p. 109-129, 1984.

51. VEDANA, M. I. S.; ZIEMER, C.; MIGUEL, O. G.; PORTELLA, A. C.; CANDIDO, L. M. B. Efeito do processamento na atividade antioxidante de uva. Alim Nutr, Araraquara, v. 19, n. 2, p. 159-165, abr./jun. 2008.

52. WANG, J.; MAZZA, G. Effects of anthocyanins and other phenolic compounds on the production of tumor necrosis factor alpha in LPS/IFN-gamma-activated RAW 264.7 macrophages. J Agric Food Chem, v. 50, n. 15, p. 4183-4189, 2002.

53. WICKLUND, T.; ROSENFELD, H. J.; MARTINSEN, B. K.; SUNDFØR, M. W.; LEA, P.; BRUUN, T.; BLOMHOFF, R.; HAFFNER, K. Antioxidant capacity and colour of strawberry jam as influenced by cultivar and storage conditions. LWT - Food Sci Technol, v. 38, n. 4, p. 387-391, 2005.

54. XAVIER-FILHO, J. Sementes e suas defesas contra insetos. Projeto Multinacional de Biotecnologia e Alimentos. Organização dos Estados Americanos - OEA, Edições UFC, Fortaleza, 1993, p. 1-3.

55. ZHANG, L.; WAN, X. S.; DONAHUE, J. J.; WARE, J. H.; KENNEDY, A. R. Effects of the Bowman-Birk inhibitor on clonogenic survival and cisplatin - or radiation-induced cytotoxicity in human breast, cervical, and head and neck cancer cells. Nutr Cancer, v. 33, n. 2, p. 165-173, 1999. 